\title{
Covid-19 vaccines:The public must have confidence in the science
}

\author{
SANDHYA SRINIVASAN
}

Keywords: Covid-19, vaccine hesitancy, transparency, immunisation, safety, efficacy

As the Covid-19 vaccine is rolled out across India, a number of reports have come in of medical professionals, healthcare workers and frontline workers refusing to take the vaccine (1). Many either do not wish to take the vaccine or would prefer to wait and watch. Such hesitancy will be a setback to a programme that is intended to benefit individuals as well as the community as a whole. This problem cannot be addressed only through better communication efforts, and coercive measures (2) are bound to backfire. The public must have confidence in the science behind vaccines in general, as well as in the research, regulatory approval, and administration. A lack of transparency in the actions of those involved-the scientific community, the pharmaceutical industry, the regulatory bodies, political parties and government-is bound to generate distrust in the vaccine.

Vaccines when adopted and administered scientifically and ethically are a public good, and universal immunisation against a package of childhood illnesses as well as specific vaccines, such as for rabies, tetanus and in disease outbreaks, are part of the government's responsibility. This requires ethical and scientific research and an evaluation and approval process establishing that the vaccine has an acceptable level of safety and efficacy according to well defined standards.

\section{Reasons for vaccine hesitancy}

Though India has among the highest levels of vaccine confidence in the world (3), individual vaccine campaigns and immunisation drives have faced resistance. The reasons for vaccine resistance include religious reservations, questions about vaccine safety; and a general distrust of science and the pharmaceutical industry. Vaccine confidence is weakened by instances of immunisation campaigns for childhood vaccines that are conducted without parents' informed consent, with a lack of transparency about vaccines' safety concerns, a reluctance to acknowledge risks and assure prompt treatment, and a failure to investigate illness following vaccination. One common, possibly overarching, driver of vaccine hesitancy is suspicion of the government's intentions, and distrust in a government health system that is unresponsive to the community's needs and opaque in its functioning (4).

Research and development of the Covid-19 vaccine in India has been marked by reports of multiple and serious ethical violations, unscientific practices, and opacity in the regulatory process. This has been true of the government's approach to the pandemic as a whole. The government has endorsed unproven drugs and therapies $(5,6)$, given approval to drugs on the basis of unscientific and unethical research (7), and drugs have been sold at huge profit margins (8). In the case of the vaccine industry, despite government support and international subsidies, vaccine companies are looking to make substantial profits out of a public health crisis (9).

Now, with the commencement of the vaccine rollout, reports of adverse events and deaths following immunisation are bound to cause concern. Unless all vaccinees are followed up, adverse events investigated properly, the findings made public, and appropriate steps taken, public distrust of the Covid-19 vaccine programme is bound to intensify.

\section{Opacity in regulatory approval}

Vaccines are different from therapeutic drugs as they are given to healthy people to protect them from a possible harm. The standards for their approval therefore ought to be higher than those for therapeutic drugs which will be used to treat or give relief to sick people. In a pandemic, vaccines with evidence will initially be approved with limited information, fulfilling scientific and regulatory requirements, and are to be given to millions of people. It is all the more important to ensure that decisions are made on the best possible evidence.

Authors: Sandhya Srinivasan (sandhya199@gmail.com), Independent Journalist, 8, Seadoll, Chimbai Road, Bandra West, Mumbai 400 050 INDIA

To cite: Srinivasan S. Covid-19 vaccines: The public must have confidence in the science. Indian J Med Ethics. 2021 Jan-Mar; 6(1) NS: 3-5. DOI: 10.20529/IJME. 2021.006

(c) Indian Journal of Medical Ethics 2021 
The legal requirement to publish certain information on drug trials on the Clinical Trials-India database has brought some information on research on drugs and vaccines into the public domain. However, essential information such as the trial protocols or the data submitted to the regulators is not available for public scrutiny.

At a time when transparency is paramount for confidence in the vaccine, the hasty and flawed approval of two Covid-19 vaccines is likely to backfire. The opacity of decision-making raises questions about the motives of each of the participants in the approval process: the Subject Expert Committee (SEC) that evaluated applications, the office of the Drugs Controller General of India (DCGI) which accepted the SEC's recommendations, and the government which is rolling out the vaccination programme.

The Serum Institute of India (SII) which is manufacturing the Oxford/Astra Zeneca vaccine is believed to have submitted incomplete data to the regulatory authorities for the vaccine's approval in India for "restricted emergency use."SIl was required to submit all available safety and efficacy data from international phase 3 trials as well as all data from a bridging study in India. The bridging study compares the immunogenicity of its product with the Astra Zeneca vaccine, and also tests it for safety in the Indian population. The bridging study is the minimum requirement for approval of drugs and vaccines developed outside India and which do not have any phase 3 data from Indian sites $(10,11)$.The reported gaps in data submitted raise the question: Were some data withheld because they were inconvenient?

The DCGI's approval for Bharat Biotech's Covaxin for restricted emergency use in "clinical trial mode" - a term that does not appear in the regulations defies explanation. Approval was given based on phase 1 and 2 trials of a few hundred children and adults, before the completion of phase 3 clinical trials of more than 25,000 people which will provide information on whether the candidate vaccine actually works, and how well it works. The minutes of the SEC reveal that the committee initially insisted on data from phase 3 trials but abruptly changed its mind and accepted challenge studies of efficacy in animals (10). Neither the SEC nor any other government body has given a credible explanation for this decision. The justification given in the SEC's minutes that the vaccine might work against mutations has been dismissed as speculation. Early approval of a drug or vaccine with limited data may be justified in a public health emergency when there is no other option. Covid-19 has a relatively low death rate, and in any case the number of new cases in India is on the decline. Bharat Biotech's application could have been deferred until safety and efficacy data from its ongoing phase 3 trial became available by March 2021.

Covaxin's approval in "clinical trial mode" apparently requires that people administered this vaccine will have to sign an informed consent document and will be followed up. This will add to confusion in the minds of vaccinees, potentially increasing vaccine hesitancy. If both vaccines are effective, why should only one vaccine require signed consent and follow-up?

One explanation for Covaxin being approved without efficacy data is that the government wanted to be able to negotiate a better price for the SII vaccine (9), or a larger quantity of it. The government's need to approve an indigenously developed vaccine also seems to be a factor for the vaccine's approval (12). But the bottom line is that the vaccine was approved without proof that it works, and is being administered to health workers across the country.

The opacity in all decision making by the SEC is possible because the names of the SEC members -- and their conflicts of interest -are never disclosed. Nor are any detailed deliberations in the public domain. Calls by senior scientists (13) to trust the regulator's decisions, even without evidence, are unwarranted.

The confusion caused by the government's silence is compounded by the incoherent responses of both companies in the media, including public spats on the safety and efficacy of each other's vaccines, followed by joint statements of solidarity (14).

\section{Ethical and regulatory violations}

A number of ethical violations have been revealed in the SII and Bharat Biotech trials. In the Bharat Biotech trial, investigators were instructed to inform participants that they would get an effective vaccine in the trial (15). At its site in Bhopal, investigators recruited victims of the 1984 gas tragedy, promising them the vaccine as well as a compensation that could have induced poor people to join. Interviews with the participants revealed violations of basic ethical and regulatory requirements such as informed consent, follow-up for adverse events, and investigation of serious adverse events (16).

Though at least one person is known to have died in the Bharat Biotech trial (16) and at least one person was hospitalised with serious neurological symptoms post vaccination in the SII trial (17), the companies have denied any SAEs. The results of the investigation of suspected, unexpected serious adverse reaction (SUSAR) have not been made public. While there is no regulatory obligation to this effect, some vaccine companies have recognised the importance of transparency in a project of this magnitude. Companies running trials of Covid-19 vaccines elsewhere have announced a pause in the trial when suspected unexpected serious adverse reactions occurred, restarting them only after an investigation concluded that there was no relation between the symptoms and the vaccine $(18,19)$.

Such violations came to light only when aggrieved participants went public. In the Bharat Biotech trial, patients along with civil society groups in Bhopal were forced to approach the media (16). An SAE in SIl's bridging study of the same vaccine was kept under cover and became public only when the participant, dissatisfied with his treatment, sent the company a legal notice. SII responded by threatening a countersuit (17). Such violations betray a contempt for clinical trial participants who risk their health for a public good. Researchers are ethically bound to treat participants with dignity and protect their health and rights.

Distrust of the research process is bound to encourage distrust in the vaccine. 


\section{Vaccine politics}

Vaccine hesitancy is one of the indirect consequences of politicising the vaccine, from promising it free in elections (20) to using it to drum up hyper-nationalistic sentiments (12). Such events create an environment of mistrust in the scientific and regulatory processes, and the vaccine. The violations and failures of scientists, pharma companies and regulators that are contributing to vaccine hesitancy should not be separated from the overall political context in which scientists work today.

\section{Acknowledgments: Sunita Bandewar and Mala Ramanathan for their valuable comments on a previous draft of this editorial.}

\section{References}

1. Rana C. COVID-19 vaccination: many doctors in government hospitals in Delhi refuse Covaxin. Caravan. 2021 Jan 16 [cited 2021 Jan 21 ]. Available from https://caravanmagazine.in/health/many-doctors-in-government-hospitals-in-delhi-refuse-covaxin

2. Angad A. 'Get vaccinated or will withhold pay': Day later, Jharkhand dist order withdrawn. Indian Express. 2021 Jan 18[cited 2021 Jan 20] Available from https://indianexpress.com/article/india/get-vaccinated-or-will-withhold-pay-day-later-jharkhand-dist-order-withdrawn-7150579/

3. Wellcome Global Monitor 2018. Appendix C: Country-level data. 2018 Aug 23[cited 2021 Jan 21]. Available from https://wellcome.org/reports/ wellcome-global-monitor/2018/appendix-country-level-data

4. Shukla M. The global threat of vaccine hesitancy. YaleGlobal Online. 2019 Mar 12. [cited 2021 Jan 21]. Available from https://yaleglobal.yale.edu/ content/global-threat-vaccine-hesitancy

5. Slisco A. India promotes hydroxychloroquine as WHO stops trials over safety issues. Newsweek. 2020 May 26. [cited 2021 Jan 21]. Available from https://www.newsweek.com/india-promotes-hydroxychloroquine-despite-who-stopping-trials-over-safety-issues- 1506658

6. Pulla P.'A fraud on the nation': critics blast Indian government's promotion of traditional medicine for COVID-19. Science. 2020 Oct 15. [cited 2021 Jan 21]. Available from https://www.sciencemag.org/news/2020/10/fraud-nation-critics-blast-indian-government-s-promotion-traditional-medicinecovid-19

7. Vaidyanathan G. Scientists criticise use of unproven drugs in India. Nature India. 2020 Nov 9. [cited 2021 Jan 21]. Available from https:// www.natureasia.com/en/nindia/article/10.1038/nindia.2020.174

8. Bhuyan A. 'Life-saving' drug in short supply: prices shoot up. HealthCheck. 2020 July 6. [cited 2021 Jan 21]. Available from https://www.healthcheck.in/life-saving-covid-19-drug-in-short-supply-prices-shoot-up/

9. Kay C, Pradhan B. Bloomberg. Delays over pricing hold back India's vital vaccine rollout. NDTV.com. 2021 Jan 6 [cited 2021 Jan 21 ]. Available from https://www.ndtv.com/india-news/delays-over-pricing-holds-back-indias-vital-vaccine-rollout-2348335

10. Srinivasan S. Approval for Bharat Biotech's COVID-19 vaccine Covaxin lacks scientific basis. Frontline. 2021 Jan 29. [cited 2021 Jan 21 ]. Available from https://frontline.thehindu.com/cover-story/missing-science-approval-bharat-biotech-covid19-vaccine-covaxin-no-efficacy-trials-published/ article33538205.ece\#!

11. Pulla P. Scientists criticise 'rushed' approval of India's COVID-19 vaccine without efficacy data. Science. 2021 Jan 5. [cited 2021 Jan 21 ]. Available from https://www.sciencemag.org/news/2021/01/scientists-criticize-rushed-approval-indian-covid-19-vaccine-without-efficacy-data

12. Pal N. DCGl's Covaxin 'approval' is political jumla. It reinforces idea of Modi's Atmanirbhar Bharat. The Print. 2021 Jan 5. [cited 2021 Jan 21$]$. Available from:https://theprint.in/opinion/dcgis-covaxin-approval-is-political-jumla-it-reinforces-idea-of-modis-atmanirbhar-bharat/579337/

13. Padmanaban G. Don't doubt Indian vaccines. Hindu. 2021 Jan 18. [cited 2021 Jan 21]. Available from: https://www.thehindu.com/opinion/op-ed/ dont-doubt-indian-vaccines/article33603184.ece

14. TNM Staff. After mudslinging, Serum Institute and Bharat Biotech declare truce. The News Minute. 2021 Jan 5. [cited 2021 Jan 21]. Available from: https://www.thenewsminute.com/article/after-mudslinging-serum-institute-and-bharat-biotech-declare-truce-140879

15. Chandna H. Covid protection with placebo too? Bharat Biotech's pitch for volunteers raises concerns The Print. 2020 Dec 28. [cited 2021 Jan 19]. Available from: https://theprint.in/health/covid-protection-with-placebo-too-bharat-biotechs-pitch-for-volunteers-raises-concerns/574697/

16. Bhuyan A. How Covaxin Trial Participants in Bhopal Were Misled. TheWire.in 2021 Jan 14. [cited 2021 Jan 19]. Available from: https:// science.thewire.in/health/peoples-hospital-bhopal-covaxin-clinical-trials-exploitation-ethics-ground-report/

17. Thacker T. Adverse event in Covishield trial in Chennai under lens. Economic Times. 2020 Nov 30[cited 2021 Jan 19]. Available from: https:// economictimes.indiatimes.com/news/politics-and-nation/dcgi-and-institutional-ethics-committee-investigating-claim-of-adverse-event-in-covidvaccine-trial/articleshow/79475211.cms

18. AstraZeneca Press release FDA authorises restart of the COVID-19 AZD1222 vaccine US Phase III trial2020 Oct 23.https://www.astrazeneca.com/ media-centre/press-releases/2020/fda-authorises-restart-of-the-covid-19-azd1222-vaccine-us-phase-iii-trial.html

19. Johnson \& Johnson statement: Johnson \& Johnson Prepares to Resume Phase 3 ENSEMBLE Trial of its Janssen COVID-19 Vaccine Candidate in the U.S. https://www.jnj.com/our-company/johnson-johnson-prepares-to-resume-phase-3-ensemble-trial-of-its-janssen-covid-19-vaccine-candidate-inthe-us

20. Singh A. Bihar polls: BJP promise of free Covid vaccine in manifesto stirs row. The Times of India. 2020 Oct 23 [cited 2021 Jan 19]. Available from: http://timesofindia.indiatimes.com/articleshow/78818536.cms?utm_source=contentofinterest\&utm_medium=text\&utm_campaign=cppst 